\title{
Sample Preparation for Materials Scientists
}

Hendrik O. Colijn

Campus Electron Optics Facility, The Ohio State University, 116 W. $19^{\text {th }}$ Ave. Columbus, OH 43210

There are many methods of preparing samples to go into the TEM [1-6] or SEM [7]. Every preparation method has advantages and disadvantages [8-11]. It is important to choose the appropriate preparation technique for the experiment. This tutorial will provide an overview of general sample requirements for analysis and the methods necessary to prepare samples. Samples may begin either as large bulk pieces or as nanoparticles or anything in between. The challenge is to be able to answer questions about the original material. While many questions can be answered using samples prepared by standard techniques, these samples are often not of sufficient quality for atomic resolution STEM imaging. [12,13]

References

[1] R.A. Anderson, S. Walck (eds), MRS Proceedings 480, Sample Preparation for Transmission Electron Microscopy IV, Materials Research Society, Boston, MA, 1997; see also MRS Proceedings 115 (1988), 199 (1990), and 254 (1992). These proceedings are the result of a number of symposia at the MRS meetings and contain useful contributions from many authors about a variety of techniques, some specialized and some general.

[2] D.B. Williams \& C.B. Carter, Transmission Electron Microscopy: A Textbook for Materials Scientists, Springer, 2004, Chapter 10.

[3] P. Echlin, Handbook of Sample Preparation for Scanning Electron Microscopy and X-Ray Microanalysis, Springer, 2009. This is a new text on the market from a well-known author.

[4] P.J. Goodhew, Specimen Preparation in Materials Science (Practical Methods in Electron Microscopy, Vol 1, No. 1) (Paperback) Elsevier Science Ltd, 1983.

[5] P.J. Goodhew, Specimen Preparation for Transmission Electron Microscopy of Materials Science; Royal Microscopy Society Handboook \#3) Oxford University Press.

[6] http://temsamprep.in2p3.fr/, website at CNRS, France with summaries of a wide range of TEM preparation techniques.

[7] J.I. Goldstein et al., Scanning Electron Microscopy and X-ray Microanalysis, $3^{\text {rd }}$ ed., Springer 2003. The standard reference work for materials SEM. There are a number of chapters on SEM sample preparation for different types of materials. The sections on electron-solid interactions also provide much useful information on important considerations when preparing samples.

[8] B.J. Kestel, Polishing Methods for Metallic and Ceramic Transmission Electron Microscopy Specimens, Argonne National Labs Report ANL-80-120, 1981. A comprehensive report on electropolishing.

[9] T.F. Malis \& D. Steele, Ultramicrotomy for Materials Science, CANMET report, also published in MRS Proceedings 199, Sample Preparation for Transmission Electron Microscopy II, Materials Research Society, Boston, MA, 1990.

[10] K.C. Thompson-Russell \& J.W. Edington, Electron Microscope Specimen Preparation Techniques in Materials Science, Monograph 5 in Practical Microscopy in Materials Science, Philips, Eindhoven, 1977. Currently out-of-print though the Techbooks edition may still be 
available from used booksellers. Extended discussion of electropolishing with a literature survey of electrolytes and conditions.

[11] L.A. Gianuzzi \& F.A. Stevie, Introduction to Focused Ion Beams: Instrumentation, Theory, Techniques and Practice, Springer, 2004. A standard reference text on FIB techniques.

[12] A. Genc, et al., Microsc. Microanal. 14 (Suppl 2) (2008) 998, submitted to Ultramicroscopy.

[13] The support of Center for the Accelerated Maturation of Materials and The Ohio State University is gratefully acknowledged.

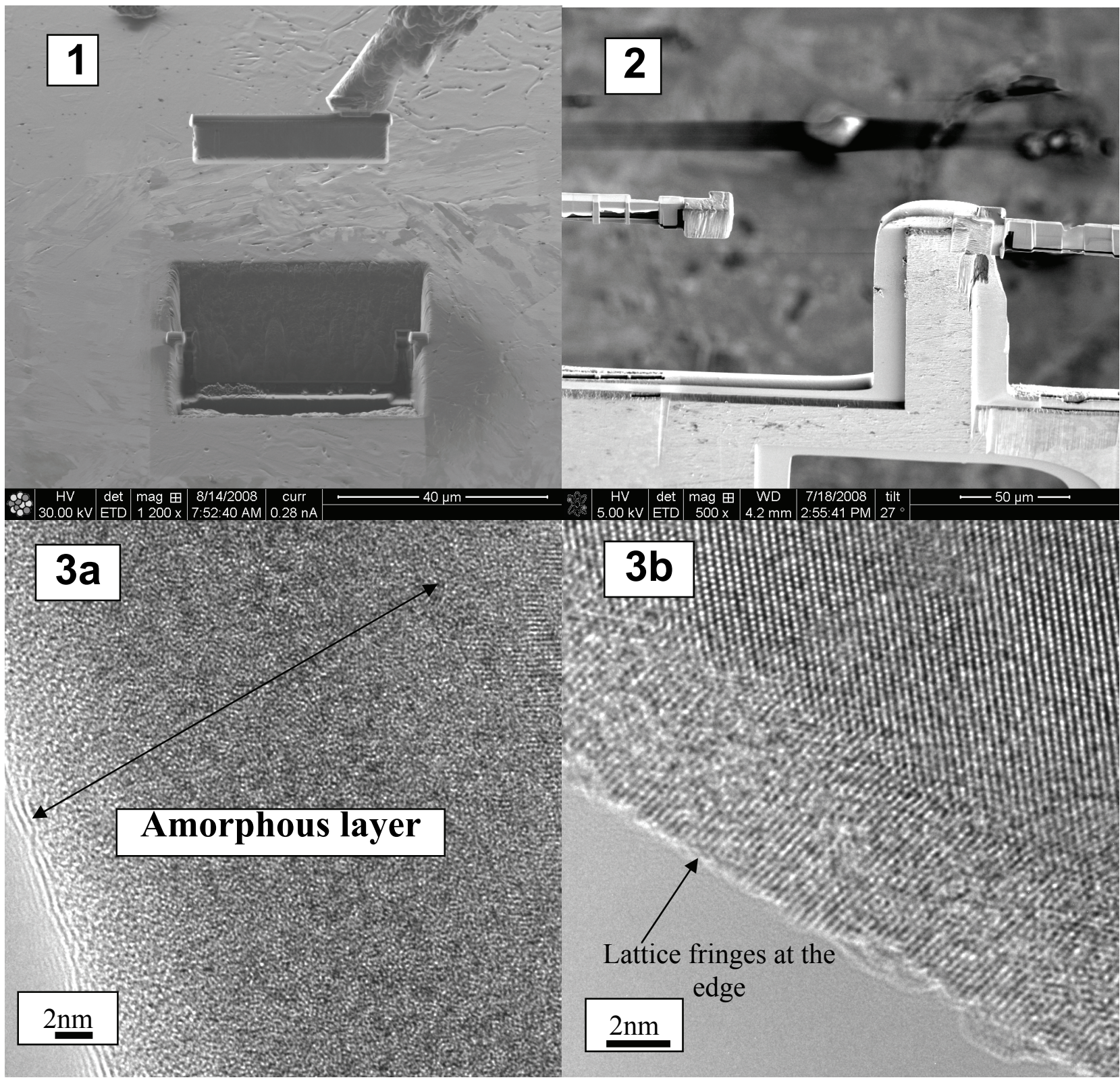

FIG. 1. In-situ FIB liftout showing sample attached to the probe by $\mathrm{Pt} / \mathrm{C}$ deposition.

FIG. 2. In-situ liftout samples attached to support posts on special $\mathrm{Cu}$ TEM grid.

FIG. 3. High resolution STEM image showing residual amorphous layer at edge of FIBbed sample (a) before and (b) after low energy Ar ion milling. [12] 